\title{
EFFECT OF MICROWAVE HEATING ON QUALITY AND FATTY ACIDS COMPOSITION OF VEGETABLE OILS
}

\author{
FLAVIA POPa, *
}

\begin{abstract}
The research was conducted in order to evaluate the microwave effect on fatty acids profile and quality parameters of safflower and rapeseed oils. To simulate conventional times used in microwave domestic cooking, different exposure times were tested: 1, 3, and 5, respectively. After 5 minutes of microwave exposure, the peroxide index showed a significant increase for both types of oil $(P \leq 0.05)$. Rapeseed fatty acids profile was rich in olei (C18:1), vaccenic $\left(\mathrm{C} 18: 1_{i}\right)$, linoleic (C18:2), palmitic (C16:0) and linolenic (C18:2) fatty acids, followed by miristic (C17:0) and stearic (C18:0) acids. Microwave heating inflicted changes in fatty acids profile of both oils, the most affected fraction was the polyunsaturated fatty acids, directly related with their higher number of double bonds, with higher susceptibility to oxidation. Microwave heating exerted more aggressive effects on safflower oil, and rapeseed oil can be exposed for 5 minutes without negative effects.
\end{abstract}

Keywords: fatty acids profile, microwave heating, peroxide index, iodine index

\section{INTRODUCTION}

Vegetable oils and fats are found in nature in plant tissue, concentrated in seeds, pulp, fruit, tubers, or germs. They are rich in monounsaturated and polyunsaturated fatty acids and contain a low amount of saturated fat [1].

Fat products are an important source of energy and are indispensable to life. Fatty acids participate in the regulation of cholesterol metabolism and are the precursors of some hormones involved in wound healing, reducing of inflammation and blood clotting. Food containing low amounts of saturated fatty acids and high linoleic acid is recommended for the prevention of coronary and heart disease. Fats rich in linoleic acid are the best natural sources of E vitamin [2].

\footnotetext{
a Technical University of Cluj-Napoca, North University Center of Baia Mare, Chemistry and Biology Department, 76A Victoriei Str., 430122, Baia Mare, Romania.

*Corresponding author: flavia_maries@yahoo.com
} 
Safflower oil has a neutral flavor that combines well with many dishes and is a rich source of unsaturated fatty acids. Daily doses of safflower oil can help to improve blood sugar, blood cholesterol, and the level of inflammation in people with diabetes. Rapeseed oil is effective in treating mild burns, abscesses, furuncles, wounds and varicose ulcers [3].

Some of the major changes that occur during processing and final preparation of heated food are due to oxidation. Polyunsaturated fatty acids autooxidation is catalysed by heat, light, trace metals or enzymes and involves free radical generation. Oxidative rancidity consists in the formation of free radicals and hydroperoxides, the transformation of unstable hydroperoxides in stable peroxides, and finally, the split into aldehydes and acids with characteristic odor $[4,5]$. It involves the oxidation of unsaturated fatty acids and generates compounds that affect food quality by altering of color, texture, nutritional value and food safety (Fig. 1).
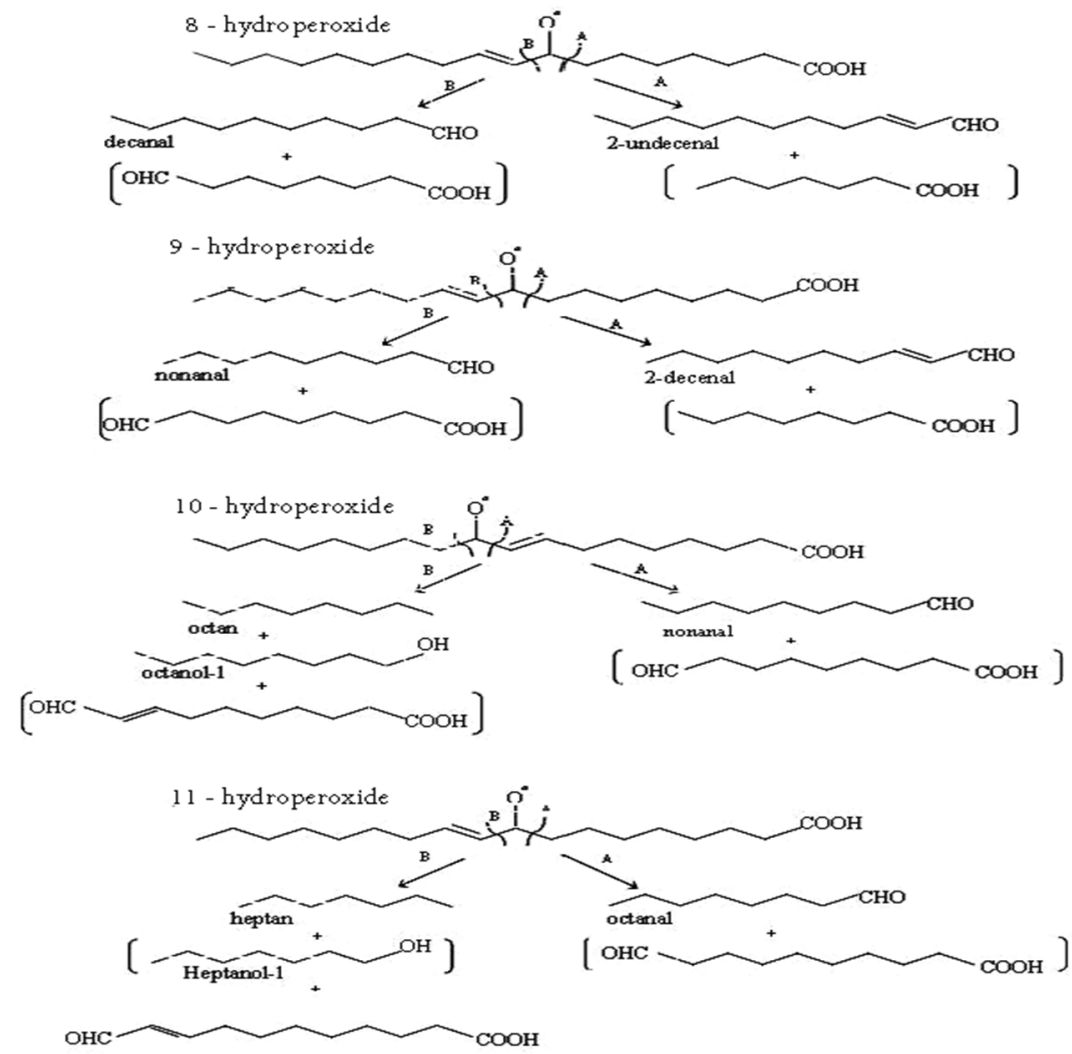

Figure 1. Breakdown of hydroperoxides from oleic acid [4] 
Several studies report quality degradation of vegetable oils during microwave heating, fatty acids degradation, reduction in bioactive compounds and properties, pigments destruction, sensorial changes, and color modifications, as well as physical and rheological changes [6-10]. Comparatively to a conventional oven heating, microwave heating induces higher and faster oils deterioration [11, 12].

The objective of the study consisted in analysis the effect of microwave assisted heating on the quality and fatty acids profile of safflower and rapeseed oils subjected to heat treatment for 1,3 and 5 minutes.

\section{RESULTS AND DISCUSSION}

Peroxide value, iodine value, refractive index value, acid value, moisture content and fatty acids profile were determined in order to asses the effect of microwave heating on safflower and rapeseed oils quality.

Free acidity represents an analytical parameter which is used to evaluate the hydrolysis extension in vegetable oils during thermal process. An increase in this parameter indicates a higher presence of free fatty acids in the vegetable oil, a direct consequence of hydrolysis, and it is an important indicator of oil chemical deterioration [13].

Safflower oil presented a lower content of free fatty acids compared to rapeseed oil. With the increase in microwave exposure, the two types of oil showed a different response. Safflower oil showed a significant increase in free acidity after 1 minute of heating compared to untreated oil $(P<0.01)$. Following 3 and 5 minutes of exposure to microwaves, the free fatty acids content increased steadily and continuously with heating time. The acidity of rapeseed oil was not significantly influenced by the increase in microwave exposure time $(P>0.05)$.

Borges et al., reported that soybean oil was not affected by the increasing exposition time, even at 15 minutes, while in baru oil, a significant increase of free fatty acids was recorded after 1 minute of heating, comparatively with unheated oils [14].

Peroxide value is a measure of primary lipid oxidation, indicating the amount of peroxides formed during oil oxidation. The products of lipid oxidation such as peroxides, free radicals, malonaldehyde and other cholesterol oxidation products are reported to promote coronary heart disease and atherosclerosis [5].

Untreated microwave oils showed lower values of the peroxide index. After 5 minutes of microwave exposure, the peroxide index showed a significant increase for both types of oil ( $P \leq 0.05)$. After 5 minutes of exposure to microwaves, 
the amount of peroxides increased 2.1 times for safflower oil and 1.8 times for rapeseed oil. The results showed that safflower oil was more unstable to heating exposure, producing higher amounts of peroxides (Table 1). With higher heating periods, both oils become oxidized, with a higher degradation of polyunsaturated fatty acids and formation of oxidation compounds.

Table 1. Effect of microwave heating on quality parameters of vegetable oil

\begin{tabular}{|c|c|c|c|c|}
\hline & $t_{0 \min }$ & $\mathbf{t}_{1 \min }$ & $t_{3 \min }$ & $t_{5 \min }$ \\
\hline \multicolumn{5}{|c|}{ Acid value (g oleic acid/100 g) } \\
\hline Safflower oil & $0.22 \pm 0.02$ & $0.41^{b} \pm 0.04$ & $0.44^{b c} \pm 0.01$ & $0.48^{c} \pm 0.03$ \\
\hline Rapeseed oil & $0.38 \pm 0.01$ & $0.35^{\mathrm{ab}} \pm 0.02$ & $0.37^{b} \pm 0.05$ & $0.40^{\mathrm{bc}} \pm 0.05$ \\
\hline \multicolumn{5}{|c|}{ Peroxide value $\left(\mathrm{mec}_{2} / \mathrm{kg}\right)$} \\
\hline Safflower oil & $3.8 \pm 0.03$ & $4.6^{\mathrm{bc}} \pm 0.06$ & $5.9^{c} \pm 0.02$ & $8.1^{d} \pm 0.01$ \\
\hline Rapeseed oil & $2.7 \pm 0.01$ & $3.5^{\mathrm{b}} \pm 0.04$ & $3.1^{\mathrm{b}} \pm 0.05$ & $4.9^{c} \pm 0.02$ \\
\hline \multicolumn{5}{|c|}{ lodine value $\left(\mathrm{g} \mathrm{I}_{2} / 100 \mathrm{~g}\right)$} \\
\hline Safflower oil & $83.1 \pm 0.3$ & $82.3^{a b} \pm 0.4$ & $80.2^{b} \pm 0.5$ & $76.5^{c} \pm 0.1$ \\
\hline Rapeseed oil & $79.8 \pm 0.2$ & $78.9^{\mathrm{ab}} \pm 0.1$ & $77.2^{b} \pm 0.2$ & $74.8^{\mathrm{bc}} \pm 0.3$ \\
\hline \multicolumn{5}{|c|}{$\begin{array}{l}\text { Refractive index } \\
\text { (refractometric degrees) }\end{array}$} \\
\hline Safflower oil & $1.473 \pm 0.01$ & $1.470^{\mathrm{ab}} \pm 0.05$ & $1.466^{b} \pm 0.06$ & $1.463^{b c} \pm 0.04$ \\
\hline Rapeseed oil & $1.469 \pm 0.04$ & $1.467^{a} \pm 0.07$ & $1.464^{\mathrm{ab}} \pm 0.03$ & $1.460^{b} \pm 0.02$ \\
\hline \multicolumn{5}{|c|}{ Moisture content (\%) } \\
\hline Safflower oil & $0.723 \pm 0.004$ & $0.711^{a} \pm 0.007$ & $0.698^{b} \pm 0.006$ & $0.693^{b c} \pm 0.003$ \\
\hline Rapeseed oil & $0.513 \pm 0.008$ & $0.504^{a} \pm 0.005$ & $0.498^{\mathrm{ab}} \pm 0.002$ & $0.490^{\mathrm{b}} \pm 0.007$ \\
\hline
\end{tabular}

Values are means of triplicates \pm standard deviation. Values with the same superscript in a column are not significantly different $(P>0.05)$.

Several authors have reported an increase in PV of oils during heating or frying [15-18]. Kreps et al., investigated the influence of microwave heating on sunflower and corn oil in two types of microwave oven. Oils were heated at progressively longer periods of $2,4,6,8$, and 10 minutes to reach approximately temperatures of $98,121,138,149$, and $158^{\circ} \mathrm{C}$. The authors found that after a 6 minutes of microwave heating the content of hydroperoxides and conjugated dienes in oils grew significantly. The study showed that corn oil resisted much better to the deleterious effects of microwave heating, due to the 2.5 times higher content of tocopherols over sunflower oil. The researchers also observed that the effect of microwave radiation on oxidation stability and content of minor constituents in oils depended not on the magnetron output alone, but of more significance appeared to be the duration of magnetron pause, interrupting the microwave heating in order to allow for heat dissipation [19]. 
Refractive index value and iodine value are measures of the degree of unsaturation of fatty acids. Safflower oil presented a higher value of refractive index compared to rapeseed oil and the values decreased significant $(P \leq 0.05)$ with the increase in microwave exposure time.

lodine index values also decreased with the increase in microwave exposure time, as a result of the reduction in the degree of unsaturation, by the split of unsaturated fatty acids double bonds. Between the iodine index and the refractive index values, there was found a direct correlation.

Fatty acids represent the main constitutes of the saponifiable fraction of vegetable oils, the fatty acids profile at $t_{0 \mathrm{~min}}$ and $t_{5 \mathrm{~min}}$ is reported for both oils.

Safflower oil fatty acids profile was dominant in oleic acid (C18:1), with levels exceeding $31 \%$, followed by arachidonic acid (C20:4) with near $19 \%$, eicosenoic acid (C20:1) with $11 \%$, and palmitic acid (C16:0) containing approximately $9.2 \%$ (Fig. 2). The linoleic (C18:2) and linolenic acid (C18:3) amounts were also important $(7.3$ respectively $6.8 \%)$.

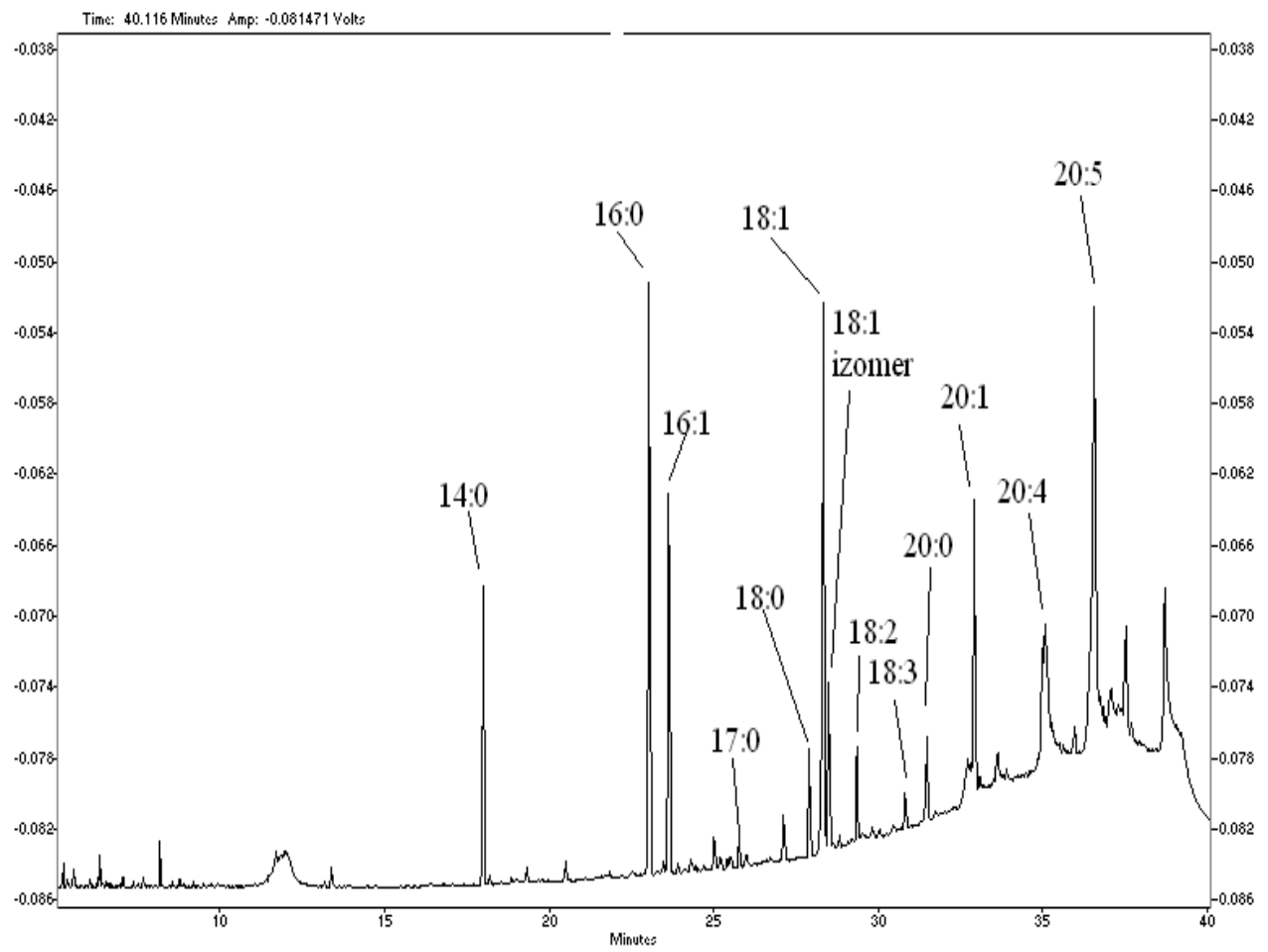

Figure 2. Gas chromatogram of unheated safflower oil 
Rapeseed fatty acids profile was rich in olei (C18:1), vaccenic $\left(C 18: 1_{i}\right)$, linoleic (C18:2), palmitic (C16:0) and linolenic (C18:2) fatty acids, followed by miristic (C17:0) and stearic (C18:0) acids (Fig. 4). Safflower oil was predominantly polyunsaturated, while rapeseed oil was mainly monounsaturated.

Microwave heating inflicted changes in fatty acids profile of both oils. Analyzing the fatty acids by their common nature, the most affected fraction was the polyunsaturated fatty acids (PUFA), directly related with their higher number of double bonds, with higher susceptibility to oxidation (Fig. 3, Fig. 5). With $t_{5 \min }$ of heating, PUFA content decreased around $10 \%$ in both oils.

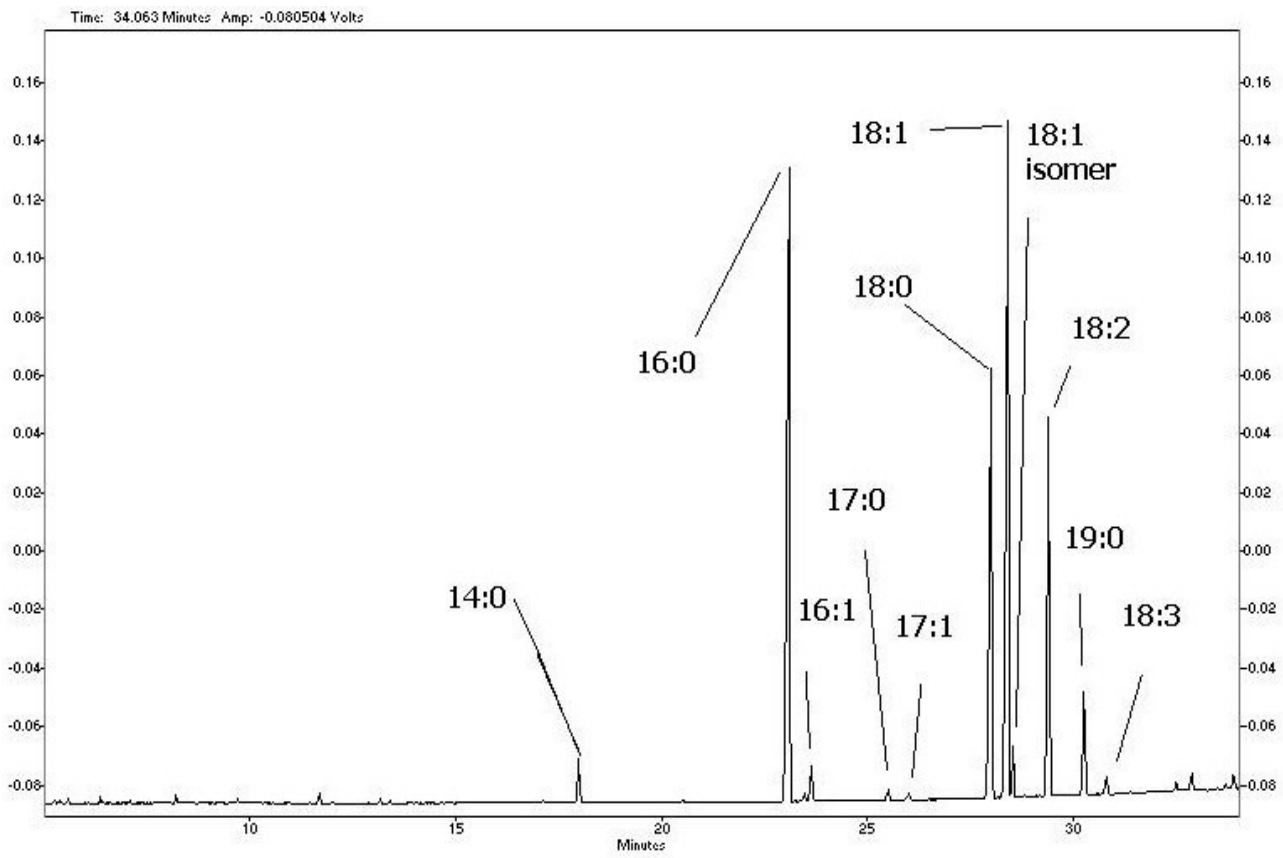

Figure 3. Gas chromatogram of safflower oil after 5 minutes of microwave heating

Kreps et al., studied the influence of microwave heating on fatty acids composition in different types of microwave oven. The researchers observed that after 10 minutes of microwave heating vegetable oils contained less than $50 \%$ original content of linolenic acid, and further heating led to complete degradation of linolenic acid in oils. Linoleic acid in microwave-heated corn oil was less degraded than in sunflower oil [19]. 
EFFECT OF MICROWAVE HEATING ON QUALITY AND FATTY ACIDS COMPOSITION OF...

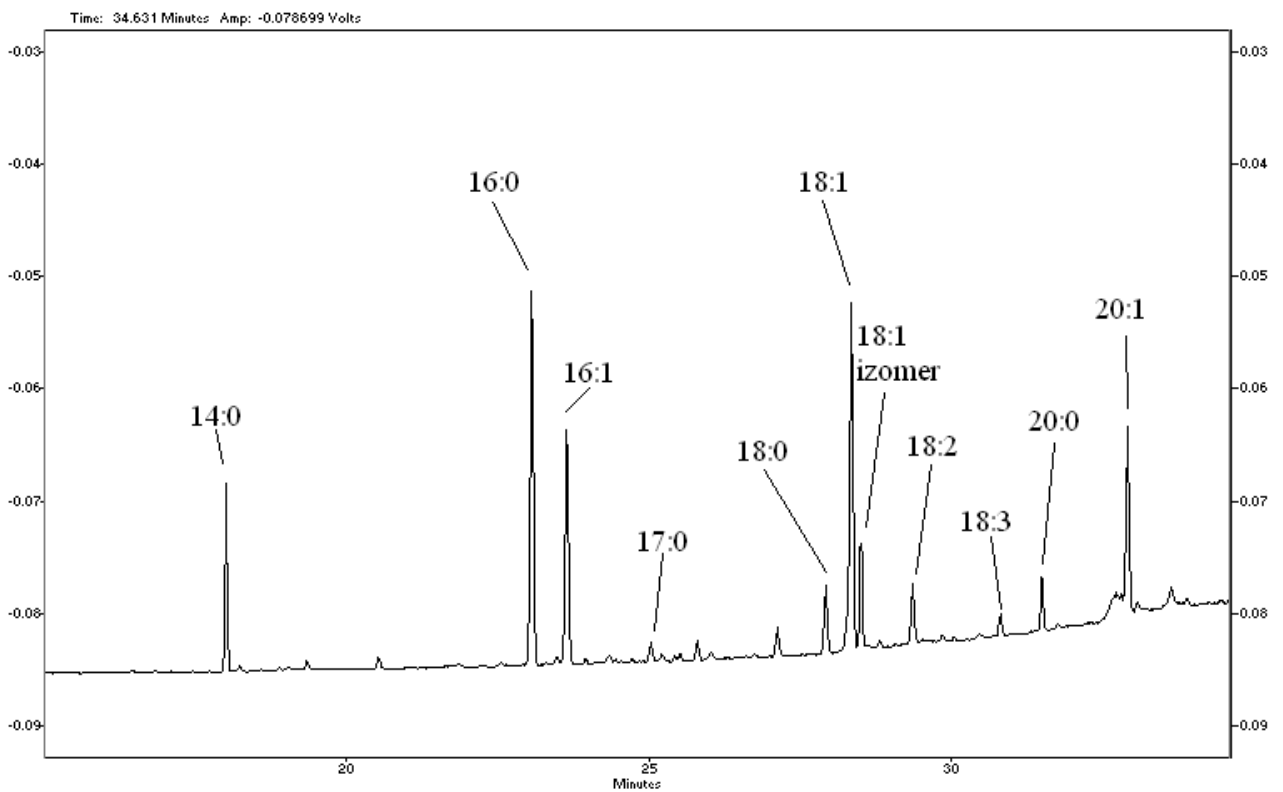

Figure 4. Gas chromatogram of unheated rapeseed oil

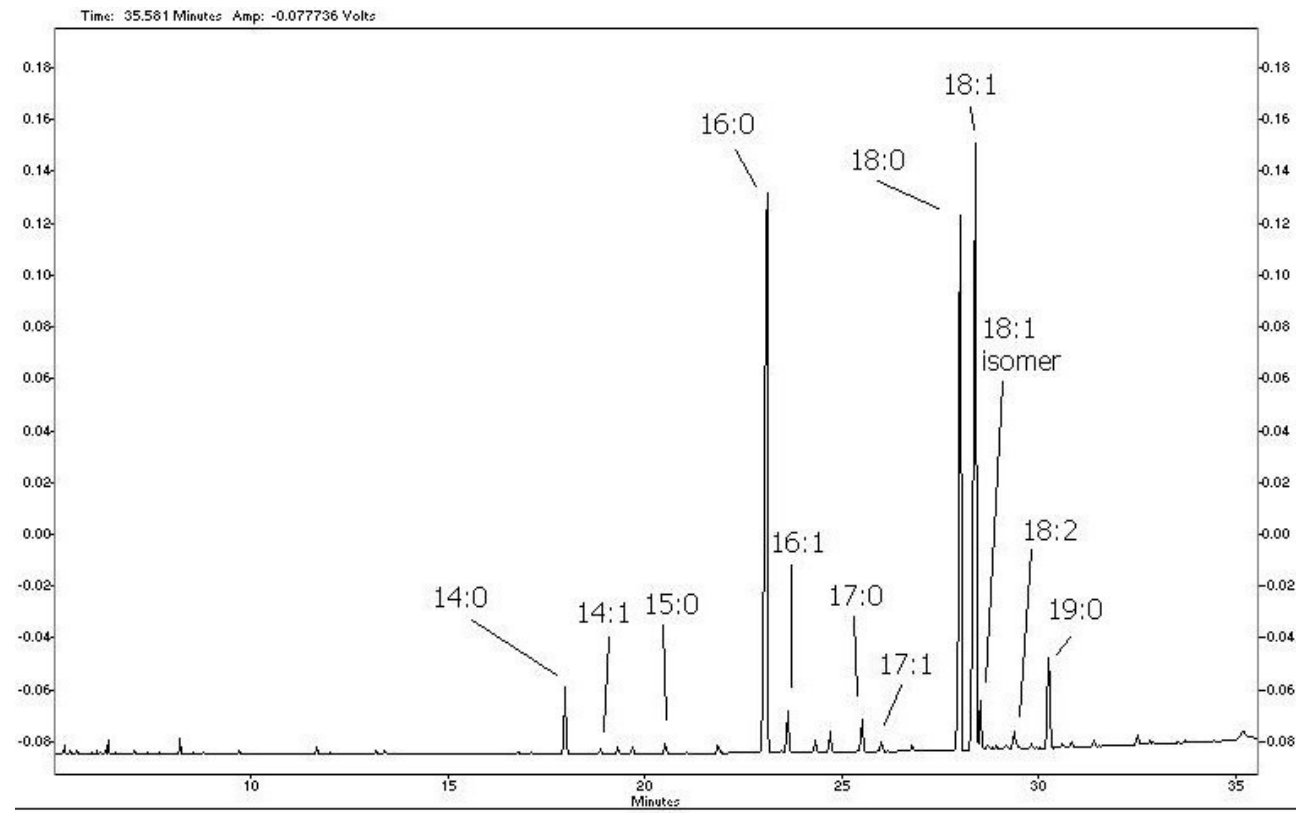

Figure 5. Gas chromatogram of rapeseed oil afer 5 minutes of microwave heating 


\section{CONCLUSIONS}

Safflower oil showed a significant increase in free acidity after 1 minute of microwave exposure. For safflower oil, there was observed a strong correlation between acidity and exposure to heat treatment, and for rapeseed oil no correlation was observed. During heat treatment no significant changes in peroxide index values were observed for exposure up to 3 minutes for both types of oil. Safflower oil was more unstable at heat treatment, producing higher amounts of hydroperoxides.

Microwave heating inflicted changes in fatty acids profile of both oils, the most affected fraction was the polyunsaturated fatty acids, directly related with their higher number of double bonds, with higher susceptibility to oxidation.

Microwave heating exerted more aggressive effects on safflower oil, and rapeseed oil can be exposed for 5 minutes without negative effects. Based on the results obtained in this work, we can state that safflower oil is very unstable when subjected to microwave heating and we recommend the use of this oil with minimal thermal processing in order to maintain its stability.

\section{EXPERIMENTAL SECTION}

\section{Samples}

To assess the behavior of safflower and rapeseed oils under microwave heating conditions, commercial samples were obtained from local markets. To simulate conventional times used in microwave domestic cooking, different exposure times were tested: 1,3 , and 5 , respectively. Within each studied oil, one sample was used as control sample (unheated - $t_{0 \mathrm{~min}}$ ). Approximately $50 \mathrm{~g}$ of oil were individually heated in Petri dishes in a domestic microwave oven at maximum power $(900 \mathrm{~W})$. The cold samples were transferred to glass tubes and kept under refrigeration until analysis. Three replications were carried out to examine each sample.

\section{Physicochemical examination}

Peroxide value was determined using UV-VIS spectrophotometer. Thiocyanate ions ( $\mathrm{SCN}-)$ react with $\mathrm{Fe}^{3+}$ ions to give a red-violet chromogen that can be determined spectrophotometrically, the absorbance of each solution was read at $500 \mathrm{~nm}$. To quantify PV, a calibration curve (absorbance at $500 \mathrm{~nm}$ vs. $\mathrm{Fe}^{3+}$ expressed in $\mu \mathrm{g}$ ) was constructed and peroxide value was expressed as meq $\mathrm{O}_{2} / \mathrm{kg}$ sample. lodine value was determined using Hanus method, was calculated as $\mathrm{g} \mathrm{I}_{2} / 100 \mathrm{~g}$ sample [20]. 
To determine the refractive index we used the PAL-RI (Tokyo, Japan) with the following technical characteristics: field: $1,3306-1,5284$; resolution: 0.0001; accuracy: \pm 0.0003 ; measuring temperature: $5-45^{\circ} \mathrm{C}$ (resolution $1^{\circ} \mathrm{C}$ ); measuring time: $3 \mathrm{~s}$; in accordance with the requirements of EMC Directive 93/68/EEC. Acid value determination consists in neutralizing acidity with sodium hydroxide $0.1 \mathrm{~N}$, using phenolphthaleine, as an indicator. Acidity was expressed as oleic acid grams to 100 grams sample [20].

Fatty acids composition was determined using a Shimadzu GC-17 A gas chromatograph (Tokyo, Japan) coupled with a flame ionization detector. The gas chromatography column is Alltech AT-Wax, $(60 \mathrm{~m} \times 0.32 \mathrm{~mm} \times 0.5$ $\mu \mathrm{m}$ ), stationary phase (polyethylene); helium was used as a carrier gas at a pressure of $147 \mathrm{kPa}$, temperature of the injector and detector was set to $260^{\circ} \mathrm{C}$, and the oven program was the following: $70^{\circ} \mathrm{C}$ for 2 minutes, then the temperature was raised to $150^{\circ} \mathrm{C}$ with a gradient of $10^{\circ} \mathrm{C} /$ minute, a level of 3 minutes, and the temperature was raised to $235^{\circ} \mathrm{C}$ with a gradient of $4^{\circ} \mathrm{C} /$ minute. Identification and quantification of FA were performed by comparison with standards. Results were expressed as $\mathrm{g} / 100 \mathrm{~g}$ fat [21].

\section{Statistical analysis}

All analytical determinations were performed at least in triplicate. Values of different parameters were expressed as the mean \pm standard deviation $(X \pm S D)$. Significant differences between mean were determined by using "Student" ("t") distribution.

\section{REFERENCES}

1. B. Sultana, F. Anwar, R. Przybylski, Food Chemistry, 2007, 104, 997.

2. C.A. Costa, A.S. Carlos, G.P. Gonzalez, R.P. Reis, European Journal of Nutrition, 2012, 51, 191.

3. S. Wang, K.A. Meckling, M.F. Marcone, Y. Kakuda, R. Tsao, Journal of Agricultural and Food Chemistry, 2011, 59, 960.

4. E. Choe, D.B. Min, Comprehensive Reviews in Food Science and Food Safety, 2006, 5, 169.

5. O. Roman, B. Heyd, B. Broyart, R. Castillo, M. N. Maillard, LWT - Food Science and Technology, 2013, 52, 49.

6. B. Roszkowska, M. Tanska, S. Czaplicki, I. Konopka, European Journal of Lipid Science and Technology, 2015, 117, 673.

7. S. Azadmard-Damirchi, F. Habibi-Nodeh, J. Hesari, M. Nemati, B.F. Achachloei, Food Chemistry, 2010, 121, 1211. 
8. M. Wroniak, K. Krygier, M. Kaczmarczyk, Polish Journal of Food and Nutrition Sciences, 2008, 58, 85.

9. A. Biswas, A. Adhvaryu, D.G. Stevenson, B.K. Sharma, Industrial Crops and Products, 2007, 25, 1.

10. A. Bendini, E. Valli, L. Cerretani, E. Chiavaro, G. Lercker, Journal of Agricultural and Food Chemistry, 2009, 57, 1055.

11. F. Caponio, A. Pasqualone, T. Gomes, European Food Research and Technology, 2002, 215, 114.

12. R.M. El-Abassy, P. Donfack, A. Materny, Food Research International, 2010, 43, 694 .

13. N. Rodrigues, R. Malheiro, S. Casal, M.C. Manzanera, Food and Chemical Toxicology, 2012, 50, 2894.

14. T.H. Borges, R. Malheiro, A. Marques de Souza, S. Casal, J.A. Pereira, European Journal of Lipid Science and Technology, 2015, 117, 503.

15. K. Warner, Journal of Agricultural and Food Chemistry, 2005, 23, 9906.

16. H. Yoshida, S. Takagi, Journal of the Science of Food and Agriculture, 1999, $62,41$.

17. F.A. Aladedunye, European Journal of Lipid Science and Technology, 2014, $116,688$.

18. F. Caponio, A. Pasqualone, T. Gomes, International Journal of Food Science and Technology, 2003, 38, 481.

19. F. Kreps, L. Vrbiková, S. Schmidt, S. Sekretár, O. Híreš, European Journal of Lipid Science and Technology, 2014, 116, 1685.

20. F. Pop, L. Mihalescu, International Journal of Food Properties, 2017, 20, 1085.

21. F. Pop, L. Giurgiulescu, A. Dumuța, Z. Voșgan, Studia Universitatis BabesBolyai Chemia, 2013, 58, 31. 